\title{
The Mind-IndePendence OF COLOUR
}

\author{
Keith Allen, University of York \\ ka519@york.ac.uk \\ European Journal of Philosophy (2007), 15:2. Please refer to the final version.
}

What do we ordinarily think colours are? The vulgar are usually assumed to think that colours are mind-independent properties of material substances, properties metaphysically on a par with shape, size and solidity. No less common, at least since the seventeenth century, is the assumption that the vulgar are mistaken in this respect: that science has shown that there is nothing that answers to this conception as such. Sometimes this is seen as the occasion to reductively identify colours with bona fide constituents of the physical world, constituents whose essential nature transcends our perceptual awareness. Sometimes this is seen as the occasion to eliminate colours from the mind-independent physical world altogether. Often, however, a more conciliatory approach is adopted. On this approach, famously proposed by Locke, colours are downgraded to the status of mind-dependent dispositional properties, dispositional properties that are partially constituted by the perceptual experiences of conscious subjects. The view that colours are part of the furniture of the world is therefore vindicated, but at the expense of the vulgar belief in their mind-independence.

The view that our common sense thought about colour is either systematically mistaken, or at best necessarily superficial, has struck some as unfortunate. Against this background, an interesting variation on the dispositional strategy therefore emerged. Rejecting the conception of colour standardly imputed to the vulgar, proponents of this approach claim that the view of colour implicit in common sense is already the view that colours are mind-dependent dispositional properties. With affinities to Berkeley's ascription of idealism to the consciousness of the 'plain man', this view has proved especially popular in Oxford, where in one form or another it has passed through successive generations of 'Oxford philosophers': from the Oxford Realists John Cook Wilson (1904) and his student H.A Prichard (1909), to amongst others, Gilbert Ryle (1949), William Kneale (1950), Michael Dummett (1979), Gareth Evans (1980), and John McDowell (1985). Not everyone working within the Oxford tradition toes the line; notable exceptions include John Campbell (1993, 2006) and Justin Broackes (1992). Still, as Kneale, describing what might nevertheless be called the 'Oxford View of Colour', puts it:

When Locke said that the secondary qualities were powers in things to produce sensations in us, he stated the facts correctly, but he did not realize that his statement was only an analysis of the plain man's use of secondary quality adjectives... When in ordinary life we say "The paper isn't really red", we always intend to imply that the paper has some other colour as a dispositional property (1950: 123). 
In the spirit of the Strawsonian enterprise of 'descriptive metaphysics' (Strawson 1959: 9), the question addressed in this paper is whether the Oxford view of colour accurately describes the structure of our ordinary thought about colour. Representative of the Oxford tradition will be the version of the view found in Evans's commentary on Chapter Two of Strawson's Individuals: 'Things Without the Mind'. Although following Strawson, Evans is primarily concerned with sound, generalising across the traditional class of secondary qualities he claims that secondary qualities are properties that we implicitly think of as dispositions of objects to appear a certain way; in the case of colour, dispositions of objects to look a certain way. (I will not follow Evans in assuming that we can generalise across the traditional class of secondary qualities: whether there are interesting differences between colour, sound, and the other secondary qualities is not a question that I will consider here.) Central to Evans's argument, and a recurring theme in discussions of colour amongst philosophers working within the Oxford tradition, is the Berkeleyan idea that the mind-independence of colour is conceptually incoherent; that we cannot conceive of what it would be for colours to be anything more than minddependent dispositions of objects to appear a certain way in the first place. As such, to attribute to common sense a view that goes beyond this - and which scientific advances could show to be false - would seem to represent, as McDowell puts it, a 'gratuitous slur on perceptual common sense' (1985: 113).

In $\$ 1$, I consider what it would mean to say of colours that they are mindindependent. In $\$ 2$, I present Evans's version of the argument that we cannot conceive of colours as anything more than mind-dependent dispositions. After setting aside two superficial responses to Evans's argument in $₫ 3$, I argue in $₫ 4$ that the view of colour Evans ascribes to common sense not only fails to do justice to our ordinary thought about colour - both as colours exist over time, and as they exist at an instant - but that more fundamentally, it fails to account for the relation that our thought about colour bears to our thought about the mind-independent existence of material substance. $\iint 5-6$ then offer a diagnosis of where the view of colour attributed to the vulgar in the Oxford tradition goes wrong. I suggest that the materials necessary to think of colours as mindindependent properties are furnished by a primitive functional theory of colour, which describes how colours relate to other properties of material substances, combined with an intuitive understanding of internal relations between the colours themselves.

\section{MIND-INDEPENDENCE}

An entity is mind-independent if its nature is not essentially dependent on the relation it bears to the mental states of conscious subjects, and their experiential mental states in particular. Something is mind-dependent, in contrast, if its nature does depend essentially on the relation it bears to the mental states of conscious subjects. Paradigmatic examples of 
mind-independent properties (which is to say, properties that are mind-independent if any are) include shape, size, and solidity; paradigmatic mind-dependent properties include being funny and being boring. Whilst we can understand what it is for something to be square independent of the way in which square things appear to perceiving subjects, we do not seem to be able to understand what it is for something to be funny independent of the reactions of perceiving subjects: whereas being square is one thing, and the experience of squareness another, at least on the face of it, what it is to be funny just is to appear funny to suitably placed, suitably receptive observers.

Following Evans, himself following amongst others Strawson (1959: 61, 69), we can say that conceiving of an entity as mind-independent requires being able to embed that entity within a simple theory of perception. To be able to embed an entity within a simple theory of perception involves recognising the implicit 'duality' of our experiences of that thing. It involves recognising, as Evans puts it, that:

on the one hand, there is that of which there is an experience (part of the world) and, on the other, there is the experience of it (an event in the subject's biography) (1980: 277; cf. 2613). ${ }^{1}$

The rationale for this criterion is to capture the intuition that our experiences are responsive to those features of the world of which they purport to be representative; for instance, that we experience a marigold as yellow because it is yellow, or that we experience a cup as round because it is round.

Recognising the implicit duality of perceptual experience in turn requires being able to conceive of that which the experience is an experience of, independent of the experience itself; as Cook Wilson puts it, we need to be able to identify 'positive content different - quite different - from [our sensory experience], and clearly distinguishable from it' (1904: 773). Without an independent conception of the entity in question, we cannot hope to make sense of the distinction between the experience and the entity necessary for recognising its mind-independent existence. Attempting to conceive of the non-experiential side of the equation - the entity in the world to which the experience is responsive - we will succeed only in reconceiving the experiential side of the equation. The problem is familiar from Berkeley and Hume. If the content of our conception of a thing is exhausted by the content of our perception of it, then as Hume says, even if we:

chace our imagination to the heavens, or to the utmost limits of the universe; we will never really advance a step beyond ourselves, nor can conceive any kind of existence, but those perceptions, which have appear'd in that narrow compass (1739-40: \$1.2.6, p. 49). 


\section{Conceiving OF THE UNPERCEIVED Existence of Colour}

Given this understanding of what is required to conceive of mind-independent existence, on which side of the mind-dependent/mind-independent divide do colours fall? The view common amongst philosophers working within the Oxford tradition is that we lack the means necessary to think about colours at one step removed from our sensory experiences of colour, and therefore implicitly think of colours as mind-dependent properties. This idea receives a particularly clear expression in the course of Evans's investigation into the nature of, and pre-conditions for, a conception of an independently existing world.

Possessing a conception of a mind-independent world requires that a subject be able to make sense of the existence of persisting grounds of the sensory phenomena that they experience; they have to be able to make sense of the idea that those grounds can exist unperceived. One of the lines of argument that Evans develops in arguing that we possess the materials necessary to make sense of an independently existing world focuses on the importance to our common sense conceptual scheme of our thought about material substance. Evans argues that we can conceive of the unperceived existence of material substance, and therefore have a conception of a mind-independent world, because we have the resources to think about the qualities essential to our conception of material objects as 'space-occupying stuff independent of the sensory experiences to which these qualities give rise. This, according to Evans, is because the sense of our spatial, primary quality, concepts is not distilled directly from sensory experience. Instead, it is determined in part by a 'primitive mechanics': 'a set of interconnected principles which make up an elementary theory...into which these properties fit' (1980: 269). In virtue of this theoretical underpinning, there is content to our conception of properties like size, shape, motion, and mass that is independent of our sensory experiences of these properties.

Our situation contrasts in this respect with that of a greatly impoverished subject, Hero, whose perceptual access to the world is exclusively auditory. We are able to conceive of the unperceived existence of secondary qualities like colour and sound, according to Evans, because we have a conception of the persisting space-occupying properties of material objects which ground the truth of secondary quality ascriptions. We grasp the truth of conditionals describing experiences that we can expect to enjoy in different circumstances in virtue of grasping facts about the persisting primary quality grounds of an object's secondary qualities. But because he thinks that Hero's conception of the auditory phenomena that exclusively comprise his world would be 'directly and exclusively...woven out of materials given in [auditory] experience', Evans thinks that Hero would be incapable of a similar conception of that which his experiences are experiences of. Without any conception of the persisting grounds of the auditory phenomena that he perceives, Hero would be unable to embed these sounds within the 
simple theory of perception necessary for an intelligible conception of mind-independent existence. He would therefore be unable to make sense of the unperceived existence of these auditory phenomena, and so have no conception of an independently existing world.

Central to Evans's argument for this conclusion is the claim that the auditory experiences Hero enjoys could not themselves serve to ground a conception of a mindindependent world. According to Evans, the auditory phenomena Hero experiences could only ground a conception of a mind-independent world if he could conceive of sounds as properties that resembled his experiences of them, but which continued to exist in the absence of those experiences. And this, Evans argues, is conceptually incoherent. We cannot conceive of secondary qualities existing unperceived, but being exactly as we experience them to be. The only way in which we can conceive of secondary qualities existing unperceived is by virtue of conceiving of the continued existence of the material substances in which they are grounded.

Evans illustrates the problem by asking whether colours, conceived of in this way, could exist in the dark. To suppose that objects are not coloured in the dark would undermine the claim that colours are abiding mind-independent properties of objects, as it would make their existence depend upon the conditions necessary for their perception: if colours can exist unperceived, then they can exist in the absence of the conditions necessary for their perception. The contrary supposition, that objects are coloured in the dark, however, at least initially appears 'quite obscure'. How could 'colour-as-we-see-it' exist when we cannot see it, and how could our experience of colour enable us to form a conception of such a state of affairs? According to Evans, it is indicative of the fact that our secondary quality concepts are woven exclusively out of the materials given in sensory experience that we cannot break the fundamental tie between sensory experience and the content of our secondary quality thoughts that the recognition of their mindindependent existence would require. Echoing Berkeley's famous argument of $\$ 23$ of the Principles of Human Knowledge: when we try to imagine an object that is red in the dark, ' $[\mathrm{w}]$ hat, after all, is being imagined but experiencing a red object that is unseen by anyone else?' (1980: 274). ${ }^{2}$

For Evans, the primary-secondary quality distinction is therefore a distinction between properties of material objects (primary qualities) whose nature is not exhaustively captured by the conception of them that it is possible to distil directly from pure sensory experience, and properties of material objects (secondary qualities) whose entire nature is captured by this conception. According to Evans, no positive content can be assigned to our conception of secondary qualities like colour independent of the content that derives directly from our sensory experiences of these properties; independent, that is, of the way objects instantiating these properties look, sound, or so on. This is not to deny that colours are properties of mind-independent material 
substances; they are still properties that exist without - in the spatial sense of being outside of - the mind. ${ }^{3}$ But unlike primary qualities, they are properties of material substance whose entire nature is revealed in pure sensory experience. They are properties of material substance to which there is nothing more than meets the eye.

\section{Imagination and Conception; Properties and Concepts}

Before getting to what I think is the heart of the problems with Evans's argument for the mind-dependence of colour, there are two objections that I want to set to one side. The first concerns the distinction between imagination and conception, the second the distinction between properties and concepts.

An instance of the worry that Berkeley assimilates thought to sensation, a common criticism made of Berkeley's claim that we cannot conceive of existence unperceived is that he is guilty of conflating sensory conception, or imagination-of, with intellectual conception, or imagination-that. According to this criticism, Berkeley simply fails to recognise the manifest difference between thinking about a tree by imagining a perceptual experience of a tree, and thinking about a tree without using any distinctively perceptual imagery. A similar criticism could be made of Evans: he ignores the distinction between thinking about an object's colour by imagining a perceptual experience of colour, and thinking about its colour without employing any distinctively perceptual imagery.

This response is certainly along the right lines. Left simply at this, however, it doesn't yet fully engage with the objection. It is not enough just to say that we can think about colour in a way that is only indirectly tied to our perception of it. The challenge is to say what this amounts to; to identify some distinctive content to the thought, in virtue of which it differs from merely imagining a sensory experience of colour. To show that the Berkeleyan is wrong, and that this challenge can be met, requires a positive proposal as to the nature of this content. (This will be attempted in $\$ \int 5-6$.)

Indeed, there is a sense in which this response is doubly irrelevant. It would hardly satisfy a thorough-going idealist to be told that we can think about the mind-independent world in a way that is only indirectly tied to sensory experience. The idealist denies that the world exists independent of conscious subjects. But in this respect, the contents of our thoughts are in no better a position than the contents of our perceptual experiences. Following Reid, for instance, Evans suggests that the primitive theory which supplies the non-sensory content necessary to conceive of primary qualities as independent of our experiences is innately given. But if this content is something that we bring to experience - and not something that receive from without in experience - then why suppose that it accurately reflects the structure of that which exists without the mind? Perhaps it merely imposes an arbitrary, though no doubt instrumentally useful, order on the information that we receive via the senses? ${ }^{4}$ 
One line of response to this worry would be to shift Evans's emphasis on questions relating to our conception of a mind-independent world to questions relating to our perception of it (cf. Cassam 2005). Instead of explaining the structure of our thought about the world in terms of forms of human sensibility exercised in perceptual experience, a more promising approach might be one that explains the character of our perceptual experience in terms of direct contact with the mind-independent world that it purports to be experience of, and subsequently explains the character of our thought about the world in terms of the character of our experience. Very roughly speaking, this is the idea behind Campbell's 'relational view of experience' (2002). ${ }^{5}$ Direct contact with the world removes, or at least reduces, the space that the mind has to shape our understanding of the world.

This is certainly an interesting line of argument. Whether it could ultimately be developed to the satisfaction of the idealist - if, indeed, this is a realistic philosophical ambition - is unclear. At any rate, it is a question that I am going to bracket. Whether we can escape the clutches of idealism is a question that arises downstream of the current inquiry.

A second response to Evans's argument that I also want to set aside emphasises a different distinction that Evans's discussion elides: the distinction between properties and concepts. Evans slips freely from talk about concepts to talk about the properties to which these concepts refer. A nice example of this is Evans's claim that 'To grasp...primary properties, one must master a set of interconnected principles' (1980: 269): what we grasp, of course, are concepts of properties, and not - unless we are literally picking up the objects that bear these properties - the properties themselves. ${ }^{6}$ But to say that there is no more positive content to our conception of colours than can be distilled directly from sensory experience is not yet to say that colours are themselves properties whose nature is exhaustively captured by this content. The most that Evans's argument establishes is that there is a conceptual distinction between primary and secondary qualities: primary qualities are qualities of which our conception outruns the conception that it is possible to form on the basis of pure sensory experience, whilst secondary qualities are qualities of which no non-sensory conception is possible. To draw from this conceptual distinction a metaphysical distinction, however, requires assuming what might loosely be called the 'adequacy' of our secondary quality concepts; it requires assuming that colours are as we ordinarily conceive them to be. But this is something that we might wish to question.

The view that colours outrun our conception of them is at least not obviously incoherent. Short of accepting some form of verificationism or transcendental idealism, there does not appear to be any a priori reason to suppose that colours must be as we conceive them to be. Even if we do ordinarily conceive of colours as mind-dependent 
dispositional properties, there would therefore be no obvious reason to rule out the possibility that they were not, for all that, mind-independent.

Still, I also want to set this response to one side. For one thing, it would certainly be cold comfort for Hero to be told that his lacking the capacity for thought about a mind-independent world is consistent with its existence. More importantly, this response comes one step too late. Doubting the adequacy of our secondary quality concepts concedes too much. To doubt the adequacy of our secondary quality concepts is to agree with Evans that the mind-dependence of colour is implicit in our ordinary thought about colour. But, as I will now argue, this is not only false to our common sense thought about colour, both as colours exist over time and as they exist at an instant, but it fails to justice to the role that colours play in our grasp of the mind-independent existence of material substance in the first place.

\section{Colour and Material Substance}

Conceiving of a quality as mind-independent requires the ability to make sense of the implicit 'duality' of our experience of it. We need to be able to distinguish between the quality and our experience of the quality. The very least that this would seem to require is that a property exhibit perceptual constancy: that we perceive the property to persist through variations in the way it appears due to changes in the conditions under which it is perceived, and at least typically, that we perceive which property it is that persists in this way. It is indicative of our ability to recognise the mind-independence of primary qualities like size and shape, for instance, that we are able to distinguish the way these qualities merely appear due to facts about the situation in which they are perceived, from the way these qualities really are: for example, that we perceive a tilted penny as really being round even though it appears elliptical when orientated in a certain way; that we perceive the trees in the distance as really being the same size as the trees in our immediate vicinity, even though they appear much smaller; and so on.

Yet colour, no less than size and shape, exhibits perceptual constancy. The way an object's colour appears depends on a wide variety of factors. Consider by way of illustration, facts about the illumination. To borrow an example from Craven and Foster (1992), turning on a desk lamp in an already day lit room brings about a very noticeable change in the appearances of the objects it illuminates. But we do not ordinarily think that turning on a desk lamp actually changes the colours of the objects it illuminates. The objects' colours appear to remain constant throughout the change in the illumination.

Acknowledging the fact that colours do not themselves change as the perceptual conditions vary is not of itself inconsistent with the view that colours are minddependent dispositions. The view of colour that Evans ascribes to common sense is at least theoretically consistent with the thought that an object's colour normally persists through variations in its appearance due to changes in the conditions under which it is 
perceived. (Conversely, it is at least theoretically consistent with the thought that the illumination can, in exceptional cases, bring about a change in an object's colour: the colours of some objects, like photographic paper and clouds, for instance, are especially sensitive to changes in light, whilst the colours of most other objects are affected by exposure to very intense light, as from a laser, or more prolonged exposure to less intense light, as when sunlight turns human skin red or brown.) The problem is the way in which Evans's view can account for the constancy of colour. According to Evans, to think about the persistence of an object's colour throughout variations in the perceptual conditions is to think about the persistence of the colour's categorical ground, the primary quality (or complex of primary qualities) in virtue of which facts about how the object would look in certain circumstances are true. As Evans says in relation to sounds:

\footnotetext{
We can think of sounds as perceptible phenomena, phenomena that are independent of us, and that can exist unperceived, because we have the resources for thinking of the abiding stuff in whose changes the truth of the proposition that there is a sound can be regarded as consisting. A fly is moving its wings; this is an event which we perceive, partly in an auditory way, and which is naïvely regarded as the ground of the proposition that, if one goes into a certain room one will hear a buzzing (1980: 278).
}

In other words, Evans thinks that we can only conceive of the persistence of secondary qualities like colour in virtue of conceiving of the persistence of something else: the persisting primary quality grounds of the disposition to appear coloured, whatever these might be. (Conversely, we conceive of a change in secondary qualities in virtue of conceiving of a change in the primary quality grounds of the disposition. $)^{7}$

But this is not the way in which we ordinarily think about colour constancy. Our belief in the constancy of colour is ordinarily grounded in the experience of constancy: we conceive of colours persisting through changes in their appearance because we perceive colours to persist through changes in their appearance. Moreover, it is the colour of the object itself that we perceive to remain constant throughout changes in the perceptual conditions. We do not perceive an object's colour to persist by virtue of perceiving the persistence of anything else. Nor do we seem to be able to make sense of perceiving the disposition to appear red as itself persisting through variations in the perceptual conditions. For what would it be to perceive an object to have the disposition to appear red when, because of the conditions under which it is perceived, the object does not appear red?

This is not to deny that we think of colours as supervening on the physical properties of material objects in which Evans grounds their dispositions to appear coloured. The point is just that we conceive of colours themselves as the grounds of an object's disposition to appear coloured; whether an object's colour is itself grounded in microphysical properties of the object is a further question, and one that we might very 
well suppose would be answered affirmatively. ${ }^{9}$ In this respect, the perceptual constancy of colour is on all fours with the perceptual constancy of shape and size. When we perceive an object to remain constant in shape or size throughout variations in its appearance due to changes in the conditions under which it is perceived, it is the object's shape or size itself that appears to remain constant. As with colours, the shapes and sizes of material objects no doubt supervene on microphysical properties of their constituent parts. But at least in the first instance, it is not our belief in the supervenience of shapes and sizes on underlying microphysical properties that explains our belief in their continued existence.

This is to say that the view of colour that Evans ascribes to common sense is false to our thought about colours as they exist over time. A related problem concerns our thought about colours as they exist at an instant. According to Evans, our thought about colour is parasitic on our thought about the primary qualities essential to our conception of material substance as space-occupying stuff. This goes hand-in-hand with thinking of colours as qualities that are, as it were, 'stretched over' the surfaces of pre-given spaceoccupying material substances, in the way that the fabric of a tent is stretched over its frame, or our clothes are stretched over our body. This is effectively the view that Berkeley ascribes to common sense, when claiming to be of a 'vulgar cast, simple enough to believe my senses, and leave things as I find them', he claims to believe that 'colours and other sensible qualities are on the objects' (1713/34: 229, emphasis added).

It might be that we think of sounds, smells, and sensory objects like rainbows and shadows, as distinct from material objects in something like this way. ${ }^{10}$ But this misdescribes the way in which we normally think of the relationship between colours and material objects. There is a world of difference between conceiving of colours as properties that lie on the surfaces of material substances and conceiving of them as properties of those objects. By way of illustration, consider the famous shadow experiment described by the German psychologist, Ewald Hering (1920: 8). If you hang a bit of paper from a silk thread in front of a lamp, so that the paper casts a shadow on a piece of white writing paper, you see the dark shadow as 'an incidental darkness that lies on the paper'. But this is not to see the darkness as a property of the paper. We only induce this aspect shift if we draw around the shadow with a black line that completely covers the shadow's penumbra. When we do this, it no longer appears as though the darkness lies on the surface of the paper. The darkness then appears to be a property of the paper.

These phenomenological shortcomings are symptomatic of a much deeper problem that Evans's view has in accounting for the relationship that our thought about colour bears to our thought about material substance. Colours allow us to distinguish, identify, and reidentify material substances (cf. Mollon 1989). Colours would be unable to play any these roles, however, if as Evans claims, our thought about the unperceived 
existence of colour were parasitic on our thought about the mind-independent existence of material substance.

Similarity or difference in respect of colour is one of the principles, described by the Gestalt psychologists, that the visual system uses to parse a scene into discrete spaceoccupants in the first place. Elements of a display that are similar in respect of colour are grouped together, whereas sharp differences in colour suggest differences in the objects whose colours they are. For instance, whilst the array on the left of Figure 1 can easily be perceived either as columns or rows, the spatially identical array on the right is more naturally perceived as four rows than four columns: the similarity in respect of colour of the dots across the rows leads us to group these dots together. Insofar as our thought about the spatial extent of an object is shaped by our thought about its colour, our thought about its colour cannot itself directly depend upon our thought about its primary qualities. This need not be deny that we think of colours as supervenient upon the microphysical properties of the parts of material substances. But it is to deny that the properties essential to our conception of material substances as space-occupying stuff shape, size, motion, weight and so on (for Evans's list, see 1980: 269) - are neither perceptually, nor conceptually, prior to colour. An object's primary qualities do not come pre-packaged in perception and thought independent of the object's colour, like the elements of a scene in a paint-by-numbers kit. ${ }^{11}$

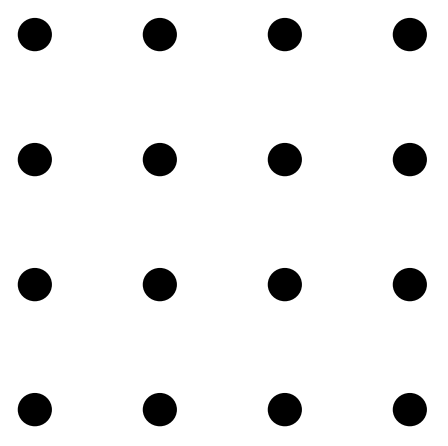

Figure 1: Gestalt Grouping Phenomenon

The array on the left can be perceived either as rows or columns, whereas it is more natural to perceive the spatially identical array on the right as consisting of four rows. After Rock (1975: 255-7).

Colours do not just serve to partition the visual scene into discrete particulars, but subsequently aid in the identification of material objects within a scene, enabling us to assign objects into higher-order categories by acting as a guide to the internal constitution of objects; as when we judge, in virtue of its colour, that an apple is ripe, a mushroom poisonous, or a cloud fit to burst. Again, to fulfil this function, our thought about the object's colour cannot depend our thought about the material substance it is a 
property of. Our thought about the object's internal constitution is mediated by our thought about its colour, not vice versa.

Colours are no less important in our thought about material substances when we move from their identification to their reidentification. One of the things that Strawson stresses (e.g. 1959: 31-6) is that questions about mind-independence are intimately bound up with questions about reidentification. Part of what is required to be able to make sense of a thing's mind-independent existence is to able to make sense of reidentifying that same thing after a gap in your experience of it. Abiding features of material objects facilitate reidentification by enabling us to keep track of objects as they come into, and go out, of view. Colours are no exception in this respect. One way of determining whether objects persist through gaps in our observation of them is by reference to the persistence of their colours. Colours could not play the role that (as a matter of descriptive fact) they play in the reidentification of particulars, however, if we implicitly thought of them as mind-dependent dispositions. According to Evans, our grasp of what it is to be coloured is parasitic upon on our grasp of what it is to be a material object. Recognising the unperceived existence of colour is supposed to rest on our grasp of the primary qualities constitutive of our conception of material bodies as persisting spaceoccupying stuff. In other words, our conception of the properties essential to material substance is supposed to explain our grasp of the unperceived existence of secondary qualities. This is the reason why Hero can supposedly have no conception of the mindindependent existence of the auditory phenomena that comprise his world: he has no non-auditory conception of that which grounds the unperceived existence of these sounds. The problem for Evans is that our conception of material bodies as abiding space-occupying stuff itself depends in part on a conception of colours as mindindependent properties. Our judgements about the persistence of material objects depends in part upon our judgements about the persistence of sensible qualities like colour; it is at least in part because we conceive of an object's colour continuing to exist unperceived that we conceive of the object as continuing to exist unperceived. But colours could only ground our judgements about the unperceived existence of material objects if we already have a conception of colours as mind-independent properties. It cannot both be the case that our grasp of the mind-independence of colour depends upon our grasp of the mind-independence of the primary qualities essential to material substance, and that our grasp of the mind-independence of the primary qualities essential to material substance depends on our grasp of the mind-independence of colour.

\section{A Primitive Theory of Colour: Functional Role}

Colours come with primary qualities like shape, size, and solidity as part of an indissoluble package. In this respect, Berkeley was right: colours and primary qualities stand or fall together. So far, however, this is just to say that the view of colour Evans 
ascribes to common sense doesn't accurately reflect what we ordinarily think colours are. It isn't yet to identify the non-sensory content in virtue of which we are able to conceive of colours as mind-independent.

Evans's objection to Berkeleyan idealism and its phenomenalist descendents rests on the thought that these theories presuppose an impoverished account of our primary quality concepts: they presuppose that the content of our primary quality concepts derives without remainder from the materials available in pure sensory experience. Whilst rejecting Berkeley's account of our primary quality concepts, however, Evans accepts the corresponding account of our secondary quality concepts: in contrast to primary quality concepts, he thinks that the content of secondary quality concepts is distilled directly from sensory experience. The result is a view that is not only false to actual thought about colour, but one that is inconsistent with the relation that our thought about colour bears to our thought about material substance more generally. What this suggests is that the Berkeleyan account of our secondary quality concepts is no less impoverished than the corresponding account of our primary quality concepts.

According to Evans, the possibility of recognising the mind-independent existence of primary qualities like shape and size depends at least in part upon the 'theoretical' nature of our spatial concepts. The primitive theory into which our spatial concepts fit supplies extra content than can be distilled directly from sensory experience, content that is necessary to be able to conceive of shape and size independent of our sensory experiences of these properties; independent, that is, of the way in which objects instantiating these properties look or feel.

At least part of the theoretical content of our primary quality concepts is concerned with how these properties contribute to their bearers' behaviour in various situations. (Another part will concern how determinates of the different determinable properties are related to each other; see \$6.) This itself comprises at least two elements. On the one hand, possessing primary quality concepts involves grasping laws of appearance. This involves understanding how our experiences of primary qualities change as objects instantiating these qualities are rotated in space, or move closer to or further away from the eye: for instance, it involves understanding that round objects tilted in space appear elliptical; that objects moving towards you appear progressively larger; and so on. It involves understanding that an object's primary qualities do not themselves change throughout these changes in their appearance: that pennies do not change their real shape when tilted in space; that the real size of objects moving towards you does not alter. And it involves understanding under which circumstances these qualities do, and do not, appear as they really are: that tilted pennies are not really elliptical; that approaching objects do not really become larger.

Laws of appearance only form part of our primitive theory of primary qualities. Grasping primary quality concepts also involves understanding how these qualities affect, 
and are affected by, properties of objects in the environment more generally. These are what we might call laws of interaction. We need to know which of an object's interactions will affect its primary qualities, and which of the object's interactions these qualities can persist through: for instance, that applying heat to a piece of wax will change its shape, whilst applying moderate pressure might not; that cutting a piece off an object will reduce its size, but that placing it on top of another object will not increase it. We also need to understand the way in which an object's primary qualities themselves contribute to its interactions with other material objects: for instance, that square pegs made of rigid material will not pass through round holes cut in rigid material whose diameter is greater than or equal to the length of their side; that lighter objects colliding with heavier ones ricochet backwards on contact; and so on.

These laws have analogues in the case of colour. Grasping our colour concepts involves implicit knowledge of how coloured objects behave in a variety of different circumstances. One thing that this involves is grasping a set of laws of appearance. As well as understanding that an object's colour does not itself change throughout changes in its appearance due (for example) to changes in the illumination, this involves understanding under which conditions the object will appear to be the colour that it really is. For instance, it involves grasping the fact that moving an object closer to a light source is generally conducive to determining its real colour. It also involves grasping the fact that some light sources are more conducive to the successful fulfilment of this task than others, in particular that good natural illumination is generally speaking to be preferred to artificial illumination: for instance, if we are unsure about what colour a garment is under the strip lighting of a shop, then we should hold it up to the window or take it outside. $^{12}$

Our grasp of what it is for something to be coloured does not depend solely on grasping laws of colour appearance. We also need to have some understanding of how colour is affected by, and contributes to, an object's interactions more generally. ${ }^{13}$ On the one hand, we need to know how the interactions into which an object enters can affect its colour: for instance, that an object's colour generally persists through changes in the illumination, but that exposure to intense heat, such as that from the sun or a fire, can alter its colour. On the other hand, we need to know how an object's colour itself affects the properties of other objects. Colours might lack the wide cosmological role of primary qualities like shape and size, but they are not wholly without causal influence. One way in which colours contribute to an object's causal powers is by affecting the colour of other objects that they come into contact with, as when we stain a white carpet with red wine or paint a canvass. It is not especially difficult to see that colours also bear some relationship to the way in which objects reflect the light that strikes them; after all, an object's colour (but not its shape or size) varies noticeably in appearance as the illumination varies. As Broackes points out, generalizations of these kinds are likely to be 
fairly rough-and-ready: the effects are not solely determined by the object's colour, but also by its spectral reflectance properties. But this does not affect their importance from the perspective of explanation and prediction. At least stated in sufficiently broad terms, generalizations of this kind are, as Broackes notes, 'quite literally true and lawlike in the sense that they are supported by their instances and support counterfactuals' (1992: 201). Nor are these the only ways in which colours contribute to their bearers' interactions; at least not if a colour's influence extends to higher-level functional and aesthetic properties of objects. On the one hand, colours have important functional and cultural significance for colour perceivers: red traffic lights mean stop, green traffic lights mean go; a referee's yellow-card serves to caution football players, their red-card serves to send them off. Colours also make an important contribution to the aesthetic properties of objects: most of us exploit some intuitive understanding of which colours go well together when deciding what clothes to wear in the morning, or how to decorate our house.

In this respect, the use of the term 'primitive mechanics' - and no less the terminological variants, 'naïve' or 'intuitive physics' - to refer to our primitive theory of the world can be potentially misleading. It is liable to suggest that our primitive theory is exclusively concerned with paradigmatically physical phenomena, like the motions and collisions of billiard balls. Whilst this is the locus of a lot of interesting psychological research, our common sense theory of the world extends far beyond the bumpings and bangings of bits of stuff. Whether or not we ultimately want to see our primitive world theory as extending all the way to the aesthetic, the scope of the primitive theory to which Evans appeals is far too narrow. ${ }^{14}$ Our colour concepts are no less 'theoretical' than concepts of properties like shape, size and mass. ${ }^{15}$

Extending our primitive theory of the world to encompass our colour concepts resolves the difficulty in accounting for the relationship that our thought about colour bears to our thought about the other properties of material substance. We no longer need to think of colours persisting through changes in their appearance, as we do on Evans's view, by thinking of the persistence of their primary quality grounds. Nor is there any room to think of the primary qualities of material substance as conceptually prior to their colours. Colours feature in the same nebulous theory as the other properties essential to our conception of material substances as space-occupy stuff. This in turn explains how we are able to exploit facts about colour in mastering the principles necessary to grasp the concepts fundamental to the idea of space-occupancy; principles which, as Evans suggests, include principles relating to 'the identity of matter perceived from different points of view...[and] the persistence of matter through gaps in observation' (1980: 269). By integrating our theory of colour into our more general primitive theory, it is intelligible how grasping facts about sameness of colour could contribute to grasping facts about sameness of substance. 


\section{A Primitive Theory of Colour: Structural Properties}

The primitive theory into which our colour concepts fit is effectively a functional theory of colour. Whilst this is necessary for a conception of colours as mind-independent, it does not exhaust the content of our common sense conception. A functional theory describes the contribution that a property makes to an object's behaviour in a variety of different situations. But, except obliquely, it does not tell us what, as it were, the property is in itself. We also need some way of thinking about the property as that which grounds and unifies the various dispositions with which it is associated. ${ }^{16}$ This requires identifying additional content to our conception of the property, content that is to at least some extent independent of the primitive theory which describes its associated dispositions.

One way of bringing out the need for additional content to our conception of colours is by noting that much of our functional theory is concerned with colours in general, as distinct from properties of different kinds: for instance, with colours as properties whose appearance is particularly sensitive to changes in illumination, as properties that can be altered by certain mechanical processes, and so on. But it is not clear that there is sufficient content in this theory to allow us to single out individual colours in thought; to know which determinate colour we are thinking about. Of course, one thing that would allow us to distinguish different determinate colours is the way that these colours appear in the appropriate conditions: for instance, that in the appropriate conditions yellow things appear yellow, red things appear red, and so on. But singling out colours in this way cannot simply involve recycling the content of our experiences of these properties in these circumstances. This is the precisely the problem that lead to the view that colours are mind-dependent in the first place. What we need is some way of thinking about individual colours that is only indirectly tied to the content of our experiences of these properties in the appropriate conditions. For instance, when we think about redness as itself persisting even though the conditions necessary for an experience of the property as red do not obtain, we need some way of thinking about redness that does not simply amount to imagining the way it would appear were the conditions different. We need some way of thinking about the property itself, as that which grounds the object's disposition to appear red. Being able to think about this property as the ground of the disposition to appear red is no less important in the limiting case where the conditions necessary for any experience of the property are not met, as in the case that Evans uses to argue for the conceptual mind-dependence of colour, when we cannot see an object because it is pitch-black. We need some way of thinking of the property that is only indirectly tied to our experience of it.

With just a primitive functional theory to rely on, the only conception that we would seem to be able to form of properties as the categorical grounds of an object's various dispositions would be a conception of a something-we-know-not-what. This would not only be metaphysically objectionable: it would be to incur a debt to what 
Cook Wilson calls (in a slightly different context) something 'even worse than "a thing in itself", viz. "an attribute in itself" (1904: 780). But epistemologically, these properties would be unable to play the relevant explanatory role. The point of recognizing the existence of these properties is to explain our conception of properties as something more than the sum total of an object's dispositions. If our conception of properties over and above the dispositions that they ground amounts to their being something-we-knownot-what, then there would be no difference to the content of thoughts about yellow, red, blue, and so on; indeed, there would be no difference to the content of thoughts about colours, shapes, sizes, solidity. But clearly there is a difference in the content of these thoughts. The thought that an object's yellowness persists though changes in its appearance due to changes in the conditions under which it is perceived is a different thought to the thought that an object's blueness persists throughout these changes; likewise, the thought that an object's colour persists throughout changes in its appearance due to changes in the perceptual conditions is a different thought to the thought that its shape or size persists through the same changes.

We therefore need an additional way of thinking about the properties of material substance than has been considered so far. Whilst our primitive theory of the world gives us a way of thinking about properties in terms of the behaviour associated with these properties, we also need to have a way of thinking about these properties that is independent of this. We not only need a primitive functional theory, but a primitive nonfunctional theory as well.

One way of thinking about colours that avoids simply recycling the content of our colour experiences is to employ cross-modal comparisons. A deeply entrenched feature of our thinking about colour is the tendency to distinguish between colours that we think of as 'warm' - yellow, red and, at least by extension, black (collectively called 'darkwarm') - and colours that we think of as 'cool' - blue, green and, by extension, white (collectively called 'light-cool'). The warm-cool distinction is robust across cultures: extending the work on 'Basic Colour Terms' of Berlin and Kay, for instance, Kay and McDaniel (1978) found that 'warm', 'cool', 'dark-warm' and 'light-cool' are amongst sixteen basic colour terms that all sufficiently evolved languages contain, the latter two invariably being the colour words contained in elementary languages with just two colour terms. The grip that this distinction has on our thought about colour is reflected in the fact that suppliers of domestic gas often use yellows and oranges to represent what are in fact blue gas flames, as in the current British Gas logo, where the blue outer parts of a flame encase an orange interior: the use of warm colours is suggestive of the benefits afforded by gas in a way that the factually correct cool colour blue is not (Gage 1999: 22). Thinking about colours by comparison with temperature represents a way of satisfying the requirement that we be able to think about colours in a way that is only indirectly tied to our sensory experiences of colour. To think about colours as 'warm' and 'cool' is not 
to think about them in terms of our experiences of colour, but in terms of our experiences of thermal qualities. ${ }^{17}$

Of course, temperature is as likely to feature on a traditional list of secondary qualities as colour. As such, this might still seem too slender a reed on which to rest our thought about colours. But it is nevertheless suggestive of the way forward. For one thing, temperature is itself naturally thought of in terms of still other properties, properties that do not feature on traditional lists of secondary qualities, namely the spatial properties higher and lower: we talk interchangeably of the temperature being hot or high, and cold or low. Insofar as we can use our thought about temperature to anchor our thought about colour, we can use our thought about spatial properties to anchor our thought about temperature. But we do not even need to take this detour via temperature. We can think about the colours themselves in spatial terms. When we think about the grey scale series of achromatic colours, for instance, we naturally think of a vertical line with black at the base, white at the top, and the various shades of grey in between. It is no less natural to think of the hues - red, yellow, green, blue and their binary mixtures orange, chartreuse, cyan, and purple - as lying around the circumference of a circle. And differences in the 'strength' of a hue can also be thought of as lying along a straight line, with a hueless achromatic colour at one end and a maximally chromatic colour at the other. Putting all this together, of course, we get a familiar three-dimensional colour solid, such as the Munsell colour solid.

Indeed, thinking about colours independent of our sensory experiences of colour need not employ other sensible properties to go proxy for the colours at all. At this point, other sensible properties can drop out of the picture altogether. Colour solids like comparisons of colours with thermal properties - represent in extrinsic (spatial or thermal) terms internal relations of similarity and difference between the colours. Distances on the hue circle, for instance, represent relations of similarity between the hues: the greater similarity of orange to red than orange to blue is represented by the shorter distance between orange and red than between orange and blue. The use of these heuristics to think about internal relations between the colours, however, is ultimately dispensable. We can think about the relations of similarity and difference between the colours directly, triangulating individual colours by their mutual inter-relations. This is a strategy standardly employed in dictionary definitions of colour, as in the OED's definition of 'green' as 'The adjective denoting the colour which in the spectrum is intermediate between blue and yellow; in nature chiefly conspicuous as the colour of growing herbage and leaves'.

Thinking directly about the relations between the colours gives us a way of thinking about the properties that stand in these relations independent of the way these properties contribute to their bearer's interactions with other objects. (Parallel stories, involving internal relations between determinates of the same determinable, can also be 
told for the paradigmatically mind-independent geometrical and space-occupying properties of objects.) On the one hand, thought about the relations between determinate colours is independent of, but no less essential for an adequate understanding of what colours are than, thought about the functional role associated with colour. To know what a determinate colour is we need to have at least some understanding of what position this property occupies within the network of determinate colour properties: we would hardly count as knowing what yellow is if we did not know that yellow is more similar to orange than it is to red, more similar to chartreuse than it is to green, and more similar to either red or green than it is to blue. At the same time, thinking about the internal relations between determinate colours is independent of thought about their interactions with perceiving subjects - how colours look - because we can think about the similarities and differences between determinate colours in sufficiently abstract terms. It is this abstract way of thinking about colours that representations of colour space formalise. The internal relations of similarity and difference in which colours stand, and that colour spaces represent, thereby afford us an independent way of conceiving of that which our colour experiences are experiences of, necessary for recognising the mind-independent existence of colour. ${ }^{18}$

\section{Conclusion: A Bipartite Conception of Colour}

The conception of colour implicit in common sense is essentially bipartite: we can think about colours both in terms of the functional role associated with colours, and in terms of the internal relations that colours bear to other colours. It is by virtue of being able to think about colours in these two complementary ways that we are able to conceive of colours as mind-independent properties. Two things need to be stressed in conclusion.

First, it should not be assumed that either aspect is more fundamental to our conception of the colours than the other; in this respect, the claim that we can effectively distinguish between what colours do (their functional role) and what they are ('in themselves') is potentially misleading. As far our common sense thought goes, there does not appear to be any reason to suppose that the distinction between the different aspects of colour amounts to anything more than a conceptual distinction: a distinction between different ways that we have of thinking about colour. In particular, there does not appear to be any reason to suppose that the two aspects are in any interesting metaphysical sense distinct. Both aspects appear to be essential to our understanding of what colours are, and there does not seem to be any question of favouring one at the expense of the other. Just as we would fail to know what yellowness is if we did not know that yellow is more similar to orange than red, we would fail to understand what yellowness (as property of material objects) is if we did not know that yellowness persists throughout variations in its appearance due to changes in the conditions under which it is perceived. 
The second point to stress is that nothing that I have said implies that the common sense conception of colour adequately represents the nature of colour. The exercise here has merely been one in descriptive metaphysics. To say that we ordinarily think of colours as mind-independent properties leaves us back at the point at which we started: with the threat that our vulgar beliefs about the nature of colour are either systematically mistaken, or at best, hopelessly superficial. The view of colour ascribed to common sense in the Oxford tradition is impervious to the deliverances of scientific theory. The view of colour that I have argued is implicit in common sense does not enjoy this advantage. Whether the common sense belief in the mind-independence of colour can be vindicated is therefore still an open question. ${ }^{19}$

1 Compare Campbell (1993: 180). In the background to this paper is the question of how Evans and Campbell can agree about the criterion for mind-independence, but disagree about whether secondary qualities like colour satisfy this criterion.

2 This argument is a mainstay of the Oxford tradition, and can be traced back at least as far as Cook Wilson. In response to G.F. Stout's claim that we ordinarily think of colours as more than mere powers to produce sensations in us, Cook Wilson objects that we are 'always thrown back on the sensation itself for positive content, and can only give a derivative positiveness to the property the body has of causing it, by thinking of it as producing this definite quality of effect' (1904: 773-4). Indeed, Cook Wilson notes that Stout's own positive description of the common sense conception of colour in effect concedes as much; according to Stout, 'When we now think of the books in the library as red, blue, green, and yellow, we think of them as they would appear to us were we there to look at them in ordinary daylight' (1904: 144). See also Prichard (1909: 86-7), McDowell (1985: 113), and, for a more linguistic formulation of this idea reflecting the dominance of ordinary language philosophy at the time - Ryle (1949: 209).

3 As Ryle puts it: 'Secondary Quality adjectives are used and used only for the publicly ascertainable facts about common objects; for it is a publicly ascertainable fact about a field that it is green, i.e. that it would look so and so to anyone in a position to see it properly' (1949: 209). See also McDowell: 'Secondaryquality experience presents itself as perceptual awareness of properties genuinely possessed by the objects that confront one. And there is no general obstacle to taking that appearance at face value' (1985: 112). In this respect it is important to bear in mind Evans's warning, at the very start of 'Things Without the Mind', that we should not conflate questions about that which is 'outer' with questions about that which is 'objective' (1980: 249).

${ }^{4}$ The assumption that our primitive theory of the world accurately describes that which exists without the mind is certainly one that psychologists working in the area sometimes deny. For general discussions of issues relating to primitive theories of the world, see Hayes (1979) and Smith and Casati (1994).

5 According to Campbell, to say that experience is 'relational' is to say that 'the qualitative character of the experience is constituted by the qualitative character of the scene perceived' (2002: 114-5). Similar ideas are explored in M.G.F. Martin's work (e.g., ms.) on naïve realist theories of perception.

${ }^{6}$ Thanks to Bill Child for bringing this example to my attention.

7 Compare McDowell, according to whom 'The weight of the explanation [of an object's looking red] would fall through the disposition to its structural ground', what McDowell describes as a 'surface texture' (1985: 118), or what we might also describe as a surface reflectance property.

8 Thanks to Justin Broackes for helpful discussion of these points. 
${ }^{9}$ I do not want to be dogmatic about this. I think we would be surprised to discover that two physically indiscernible objects could differ in colour. But I am not sure that the common sense commitment to the mind-independence of colour strictly speaking demands the supervenience of colours on microphysical properties. At any rate, even if we happen to accept the supervenience of colours on microphysical properties, it at least seems, as Campbell remarks, that the view that colours are the grounds of dispositions to appear coloured 'would be available even to someone who rejected the atomic theory of matter: someone who held that matter is continuous and that there are no microphysical properties' (1993: 178).

${ }^{10} \mathrm{It}$ is telling that, foreshadowing his later line of argument, Evans remarks that if our Hero is to think of his experience as of a world, and this world is not to be a spatial world, it will be a world composed of phenomena analogous to our sounds, smells, and rainbows, rather than to our material substances' (1980: 263-4). This way of understanding the difference between colours and sounds, smells, and sensory objects more generally, is suggested by M.G.F. Martin (ms).

11 This is reflected in the phenomenon of neon colour spreading. Modal completion, when subjective figures 'pop out' from their background, as in the case of Kaniza figures, is often accompanied by colour spreading, in which colour spreads from neighbouring regions into modally completed areas from which it is physically absent, thereby allowing attention to spread across the completed object's surface. For discussion, see Davis and Driver (1997).

12 The importance of laws of appearance to our colour concepts is illustrated by Sellars's 'Myth of John'. Sellars considers someone who has only ever seen colours under standard conditions, and so does not understand that for something to be green is for it to be such that it looks different under different illuminations. On being told that a blue tie which appears green under electric illumination merely appears green, John is confounded: 'Well, this is a pretty pickle. I just don't know what to say' (1959: \$15).

${ }^{13}$ For further discussion of these points, see Broackes (1992) and Campbell (2006).

${ }^{14}$ Some of the Gestalt psychologists, from whom the contemporary idea of a primitive world theory more or less directly developed, certainly thought that our common sense theory of the world encompasses questions of value (Smith and Casati 1994). As Köhler remarks, for instance: 'The layman believes that he often feels directly why he wants to do certain things in a first situation, and certain other things in a second... He maintains that he feels how many of his attitudes grow from things and situations as adequate responses' (1947: 320-322). Amongst the examples Köhler gives are admiring a serious, calm confident alto voice, being charmed by a child's first smile, and enjoying a cold beer on a hot day.

15 Which is not, of course, to deny that colours are observable. As Evans remarks in relation to an object's primary qualities: 'to deny that these... properties are sensory is not at all to deny that they are sensible or observable' (1980: 269-70). For an interesting discussion of the distinction - or lack thereof - between theoretical and observational knowledge, drawing on Evans's discussion in 'Things Without the Mind', see Broackes (2007: §4).

16 The importance of thinking of colours as the grounds of an object's disposition to appear to coloured is something emphasised by both Campbell (1993, 2006; for general discussion of categorical grounds, 2002: Chapter 12) and Broackes (1992: 203-7). It is also something stressed by Strawson in his response to Evans. Strawson agrees with Evans that a 'deep conceptual prejudice' of ours is offended by the attempt to explain facts about persisting entities in terms of ungrounded dispositions. But he thinks that the physical properties in which Evans grounds the truth of secondary quality ascriptions are not obviously any better off in this respect than the secondary qualities themselves. Hence the rhetorical force of his claim that 'If it seems true of the sensory properties in general that they all dissolve together, under reflective pressure, into dispositions, this seems even more certainly true of the "physical" properties which are held to constitute their categorical base' (1980: 280). In this respect it is interesting to contrast Ryle (1949), who embeds the Oxford view of colour within a wholly general dispositional theory of properties. 
17 There are a number of other more or less robust ways of thinking about colour in comparison with other properties and affective states: we can think of colours as receding or advancing, active or passive, masculine or feminine, and so on.

18 There are important similarities between the non-functional theory of colour outlined here, and Broackes's (1992: 207-8, 214) account, building on Wittgenstein's Remarks On Colour, of 'the scheme of explanation' in which our common sense thought about colour is embedded. A fuller development of the non-functional theory would take into account the additional relations that Broackes mentions. I am suggesting that thinking about internal relations between the colours offers a way of thinking about colours that is not directly tied to our experience of colour, and so provides the conceptual resources to think of colours as the mind-independent grounds of an object's dispositions to appear coloured. Broackes does not appear to use his remarks about the scheme of explanation in which colours are embedded for a similar purpose.

19 I would like to thank Justin Broackes, Bill Child, Tim Crane, Mark Kalderon, Mike Martin, Scott Sturgeon, an audience at Oxford, and a referee for the European Journal of Pbilosophy, for comments and questions. For more general discussion of the structure of our thought about the world, thanks to the UCL Strawson Reading Group, particularly Mathilde Jacobsen, Will McNeill, Joel Smith, Tom Smith, and Ann Whittle. This research was made possible by a Jacobsen Research Fellowship in Philosophy from the University of London.

\section{REFERENCES}

Berkeley, G. (1713/34), Principles of Human Knowledge, (ed.) M. Ayers. London: Everyman, 1975.

Broackes, J. (1992), 'The Autonomy of Colour', reprinted in A. Byrne and D. Hilbert, D (eds.) Readings on Color i. Cambridge, Mass.: MIT Press, 1997.

- (2007), 'Colour, World and Archimedean Metaphysics: Stroud and the Quest for Reality', Erkenntnis.

Campbell, J. (1993), 'A Simple View of Colour', reprinted in A. Byrne and D. Hilbert, D (eds.) Readings on Color i. Cambridge, Mass.: MIT Press, 1997.

(2002), Reference and Consciousness. Oxford: Oxford University Press. (2006), 'Manipulating Colour', in T. Gendler and J. Hawthorne (eds.) Perceptual Experience. Oxford: Clarendon Press.

Cassam, Q. (2005), 'Space and Objective Experience', in J. Bermudez (ed.) Thought, Reference and Experience. Oxford: Oxford University Press.

Cook Wilson, J. (1904), 'Primary and Secondary Qualities', in A. Farquharson (ed.) Statement and Inference ii, Oxford: Oxford University Press, 1926.

Craven, B. and Foster, D. (1992), 'An Operational Approach to Colour Constancy', Vision Research 32: 1359-66.

Davis, G. and Driver, J. (1997), 'A Functional Role for Illusory Colour Spreading in the Control of Focussed Visual Attention', Perception 26 1397-1411.

Dummett, M. (1979), 'Common Sense and Physics', in G.F. MacDonald (ed.) 
Perception and Identity. London: MacMillan.

Evans, G. (1980), 'Things Without the Mind', reprinted in Collected Papers. Oxford: Clarendon Press, 1985.

Gage, J. (1999), Colour and Meaning. London: Thames and Hudson.

Hayes, P. (1979), 'The Naive Physics Manifesto', reprinted in M. Boden (ed.) The Philosopby of Artificial Intelligence. Oxford: Oxford University Press, 1990.

Hering, E. (1920), Outlines of a Theory of the Light Sense, (trans.) L. Hurvich and D. Jameson. Cambridge, Mass.: Harvard University Press, 1964.

Hume, D. (1739-40), A Treatise of Human Nature, (eds.) D. Norton and M. Norton Oxford: Oxford University Press, 2000.

Kay, P. and McDaniel, C. (1978), 'The linguistic significance of the meanings of basic color terms', Language 54: 610-646.

Kneale, W. (1950), 'Sensation and the Physical World', Philosophical Quarterly 109-126.

Köhler, W. (1947), Gestalt Psychology. New York: Liveright Publishing.

Martin, M.G.F., (ms.), Uncovering Appearances.

McDowell, J. (1985), "Values and Secondary Qualities", in T. Honderich (ed.) Morality and Objectivity. London: Routledge.

Mollon, J. (1989), ““Tho' She Kneel'd in That Place Where They Grew...”: The Uses and Origins of Primate Colour Vision", reprinted in A. Byrne and D. Hilbert, D (eds.) Readings on Color ii. Cambridge, Mass.: MIT Press, 1997.

Prichard, H.A. (1909), Kant's Theory of Knowledge Oxford: Clarendon Press.

Rock, I. (1975), Introduction to Perception. New York: Macmillan.

Ryle, G. (1949), The Concept of Mind. Harmondsworth: Penguin Books.

Sellars, W. (1956), Empiricism and the Philosophy of Mind. Cambridge, Mass.: Harvard University Press, 1997.

Smith, B and Casati, R. (1994), 'Naive Physics: An Essay in Ontology', Philosophical Psychology 7: 225-244.

Stout, G.F. (1904), 'Primary and Secondary Qualities', Proceedings of the Aristotelian Society 4: 141-160.

Strawson, P.F. (1959), Individuals. London: Methuen.

— (1980), 'Replies', in Z. van Straaten (ed.) Philosophical Subjects. Oxford: Clarendon Press. 